\title{
STUDY OF SURFACE INTEGRITY BASED ON MILLING OF MATERIAL AISI 316L
}

\author{
Mailis Polma, Tonu Leemet, Marten Madissoo \\ Estonian University of Life Sciences, Estonia \\ mailis.polma@emu.ee, tonu.leemet@emu.ee,marten.madissoo@emu.ee
}

\begin{abstract}
Spontaneous" cracking of the material or lack of resistance to corrosion areone of the biggest complications is described by material surface integrity, which is resulting from the machining of the material. To describe the material surface integrity after material removal process via machining it is important to studythe influence of the cutting forces. A known fact is that during cutting of material the cutting parameters, such as cutting speed, depth and feed have each a different effect on the value of the cutting force. In recent years there have been several studies to investigate how and what most influences the value of cutting forces in milling. Nevertheless, there is little information about its effect to the surface integrity. Different materials act variously during the cutting process, and therefore it is essential to know the impact of the cutting forces on the material surface integrity. Knowing the influence of the cutting forces helps determine what kind of equipment, such as machine and tools are best to use to improve the quality when milling. This paper focuses mainly on the effect of different cutting parameters upon the quality of material AISI 316L. Case study was developed to determine various relations between the cutting parameters and material surface integrity. Part of the experiment was conducted using coolant and the other part without coolant. During milling of the material AISI 316L the cutting forces were measured. In this experiment residual stress and surface roughness, which also describe the material surface integrity, were measured. Main data analysis, comparison of predicted and given results, was made with the program Modde Pro. The study showed that cutting feed has significant effect on the value of the cutting force and residual stress. The other parameter that influenced the cutting force was the cutting depth. Cutting speed had the smallest impact on the value of the cutting force. With given results it is possible to infer that the feed rate also influences the material surface integrity the most. From the results it follows that the feed rate has considerable effect on the surface quality.
\end{abstract}

Keywords: surface integrity, AISI 316L, residual stresses, milling.

\section{Introduction}

In nuclear industry, when producing parts for power plant equipment, it is crucial to use suitable materials. Austeniticstainless steels arecommonly used materials in various sections in nuclear power plants due to the materials ductility and resistance to corrosion [1]. AISI 316L is one of the most used, because in addition to corrosion resistance, it has good welding properties. It is widely used in places like cooling pumps, pistons, generators and pressure machines [1]. It is often that these parts need to operate under considerable mechanical loading combined with chemically aggressive ambient environment [2]. Therefore, it is essential to minimize the potential effects hindering the integral properties of the part material that may originate from its manufacturing process.

Material surface integrity is the result after all the material processing has been done. In general, it can be divided into two parts. The first part describes the surface quality (geometrical skin) and it is described with the surface roughness profile. The second part is the internal structure, which is described with residual stresses, stress corrosion cracking (SCC) and changes in the material mechanical properties, like hardness[3]. In this research paper the possible effect of metal cutting to the surface integrity is investigated. For the quantitative analyses the cutting forces from the milling operation are chosen as a subject of the study. From the received values of the cutting forces it is possible to assess changes in the material internal structure, which are described with stress corrosion cracking and material mechanical properties.

Residual stresses are mechanical stresses, which will remain into the material after material processing [4]. These stresses are locked in cracks near the surface of the material. It is known that residual stresses can at some instances cause the macroscopic failure of a component. Therefore, it is essential to reduce residual stresses in material [5]. Residual stress might stem from different sources. Here a particular hypothesis is investigated - what are the effects of the cutting forces to the surface integrity.

The purpose of this study is to give an assessment of the effects of the cutting parameters on the surface integrity of AISI 316L, when using the traditional milling method. This enables to predict the effect of the cutting forces to the residual stresses and surface roughness, when changing the cutting parameters. 


\section{Material and methods}

The material in this analysis is widely used AISI 316L austenitic stainless steel. The optimal dimensions for the test pieces were calculated to fit in LANG vices with secure clamping on $3 \mathrm{~mm}$ and

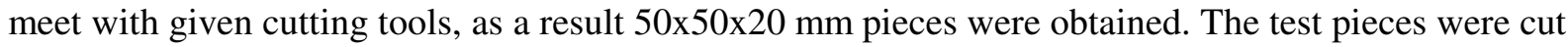
using water-jet cutting to reduce the thermal effect and material chemical processing, which can have an impact on residual stresses in materials. For cutting the material traditional milling method, face milling, was used. It is known that tool wear influences the value of the residual stress and surface roughness [6]. To minimize the tool wear effect in each attempt new cutting edge was used. To ensure gradual entry into the material the method of roll-in technique was used. After cutting the material a visual control was carried out to detect any surface defects before further analysis.

The experiments were carried out using the HAAS SMM-HE Super MiniMill. Required cutting tools were provided by SandvikCoromant. For milling the R245-032A32 face mill was used, A1B204032 tool holder and R245-12 T3 inserts. For chip removal and cooling the test pieces half of the trials were carried out with coolant Blasocat 2000 Universal, and the other half with compressed air.

For measuring the cutting force the Kistler 9257B dynamometer was used. In each test run the dynamometer was measuring the dynamic cutting forces, which later were displayed using data analysis software Dynoware.

Material surface roughness was measured after milling with Mitutoyosurftest SJ-210. Each test piece was measured three times on a planar surface with fixed equipment in laboratory conditions.

Material residual stresses were measured using the x-ray diffraction method. Samples analysis ware carried out in three different angles 0,45 and 90 degrees. Four of the test pieces were electropolished to measure the residual stress profile in these pieces.

Test plan was composed with the assistance of $U$ metrics freeware program Modde Pro version 10.1. For each cutting parameter, such as the feed rate, cutting depth and the cutting speed, the minimum and maximum values were given. These values are presented in Table 1. Responses to given values are presented in Table 2 .

Table 1

Given values of cutting parameters

\begin{tabular}{|c|c|c|}
\hline \multirow{2}{*}{ Cutting parameter } & \multicolumn{2}{|c|}{ Value } \\
\cline { 2 - 3 } & Cutting with coolant & Cutting with compressed air \\
\hline Cutting feed, $f_{z}$ & 0.15 to $0.35 \mathrm{~mm} \cdot \mathrm{th}^{-1}$ & 0.1 to $0.28 \mathrm{~mm} \cdot \mathrm{th}^{-1}$ \\
\hline Cutting depth, $a_{p}$ & 1 to $3 \mathrm{~mm}$ & 0.5 to $2.5 \mathrm{~mm}$ \\
\hline Cutting speed, $v_{c}$ & 150 to $200 \mathrm{~m} \cdot \mathrm{min}^{-1}$ & 120 to $170 \mathrm{~m} \cdot \mathrm{min}^{-1}$ \\
\hline
\end{tabular}

Table 2

Responses to evaluate surface integrity

\begin{tabular}{|c|c|}
\hline Response & Unit \\
\hline Surface roughness & $\mu \mathrm{m}$ \\
\hline Cutting Force & $\mathrm{N}$ \\
\hline Residual stress & $\mathrm{MPa}$ \\
\hline
\end{tabular}

\section{Results and discussion}

\section{Cutting force}

For a good model it is important that the observed values (green dots) are close to the straight line, like in Fig. 1d. In Fig. 1a a replicate plot is shown with the observed responses. This plot shows variation in the results. All replicates are coloured blue and experiments green. With given results repeated specimens values are close together, meaning that the created model is good. Fig. 1b describes the model fit (R2) with given results, estimated future prediction precision $(\mathrm{Q} 2)$, model validity (MV) and reproducibility (Rep). Values of R2 and Q2 are both higher than 0.5 (maximum values are 1) and the values being close together indicates that the model is good. High values of MV and Rep also confirm the fact that the model fit is succeeded. 
Fig. 1c shows that first and foremost the value of the cutting depth has the biggest effect on the cutting force. Also cutting feed has an effect. To see any interaction between the cutting feed and the depth the square test was performed and it indicated cumulative response. In the value of the cutting force the cutting speed does not have an effect.

Knowing that the model is good for further analyses, it is possible to predict what could be the values of the cutting force. To be able to do that one of the cutting parameters, such as the cutting feed, is set constant. In Fig. 2 the value of the cutting feed is set the highest level possible in this experiment and in Fig. 3 it is set the lowest.

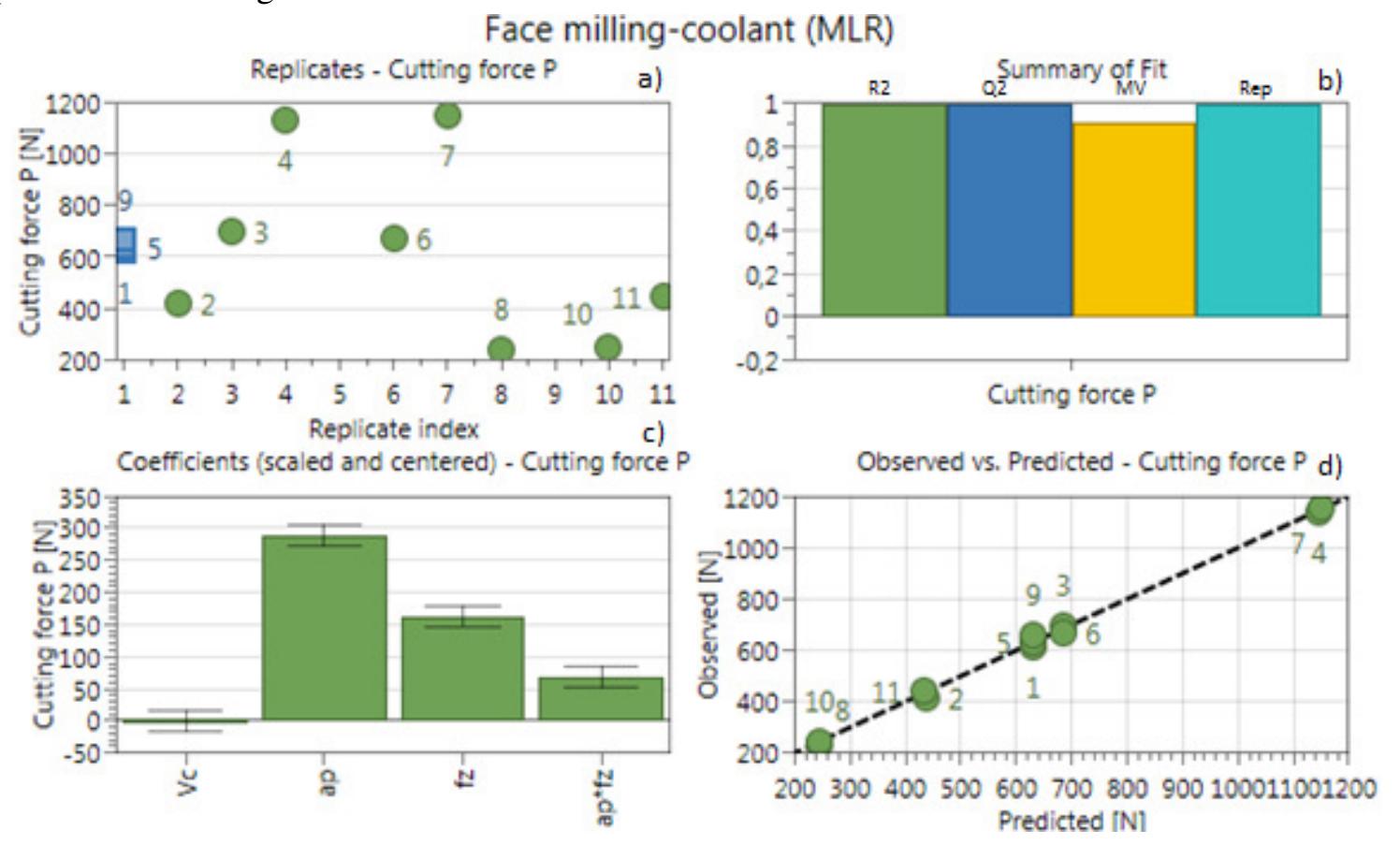

Fig. 1. Statistical comparison between predicted and collected data of cutting force: a - replicate plot; $b$ - model validity parameters; $c$ - cutting parameter effect to value of cutting force; $d$ - outcome of response versus predicted values
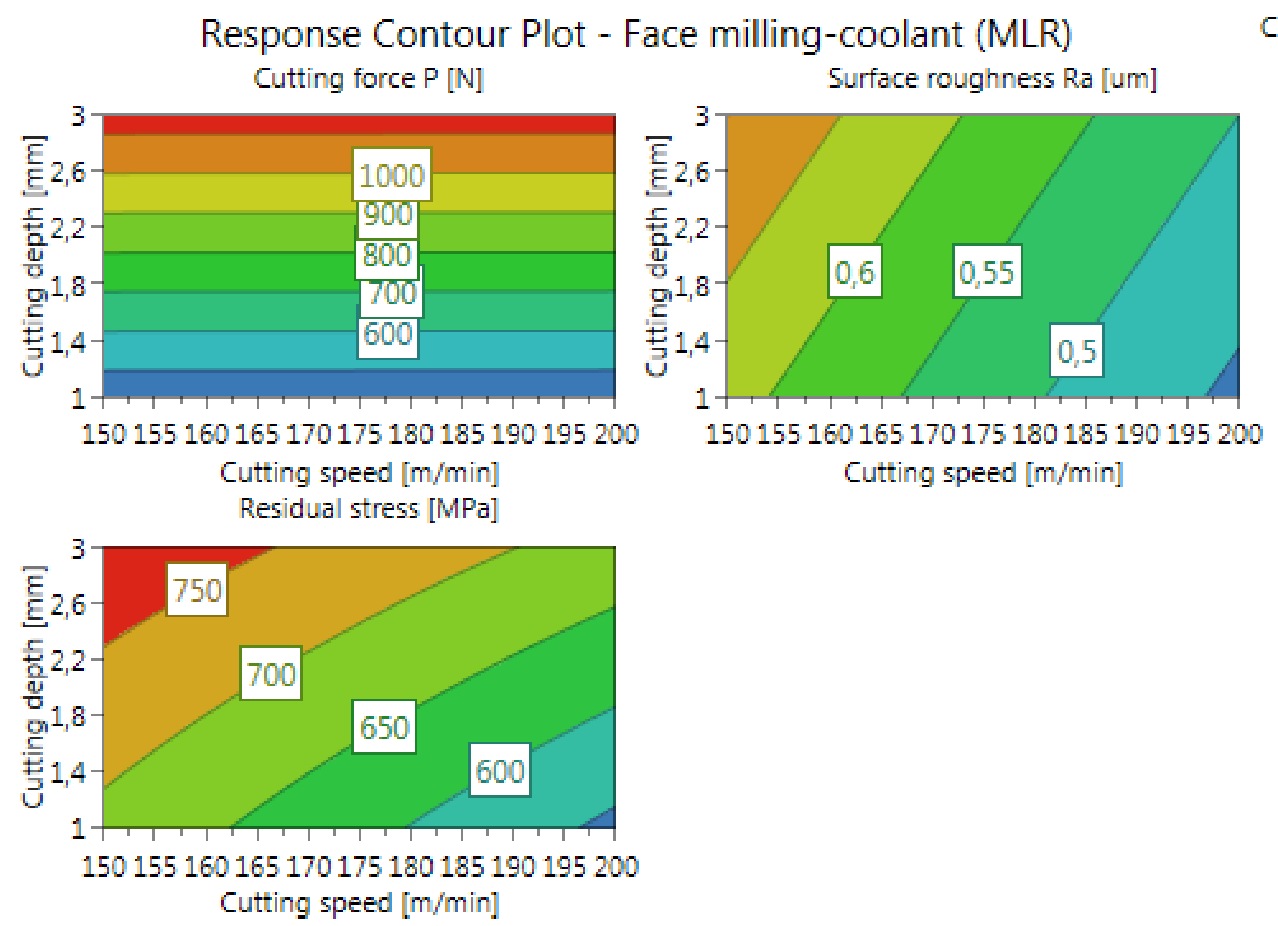

Fig. 2. Predicted values of residual stress, surface roughness and cutting force, when cutting parameters depth and speed are variables and cutting feed constant $f_{z}=0.35 \mathrm{~mm} \cdot \mathrm{th}^{-1}$ 
In Fig. 4-6 it is shown what kind of and how accurate the effects of the cutting parameters are. In Fig. 4 and 6 the cutting feed and depth have increased linear response. However, the results given in Fig. 5 indicate that changing the value of the cutting speed has no reaction to the cutting force. To get the most precise prediction the white area between the lines in given results should be as narrow as possible. The results in Fig. 4-6 indicate that predictions are straight with confidence being $95 \%$.

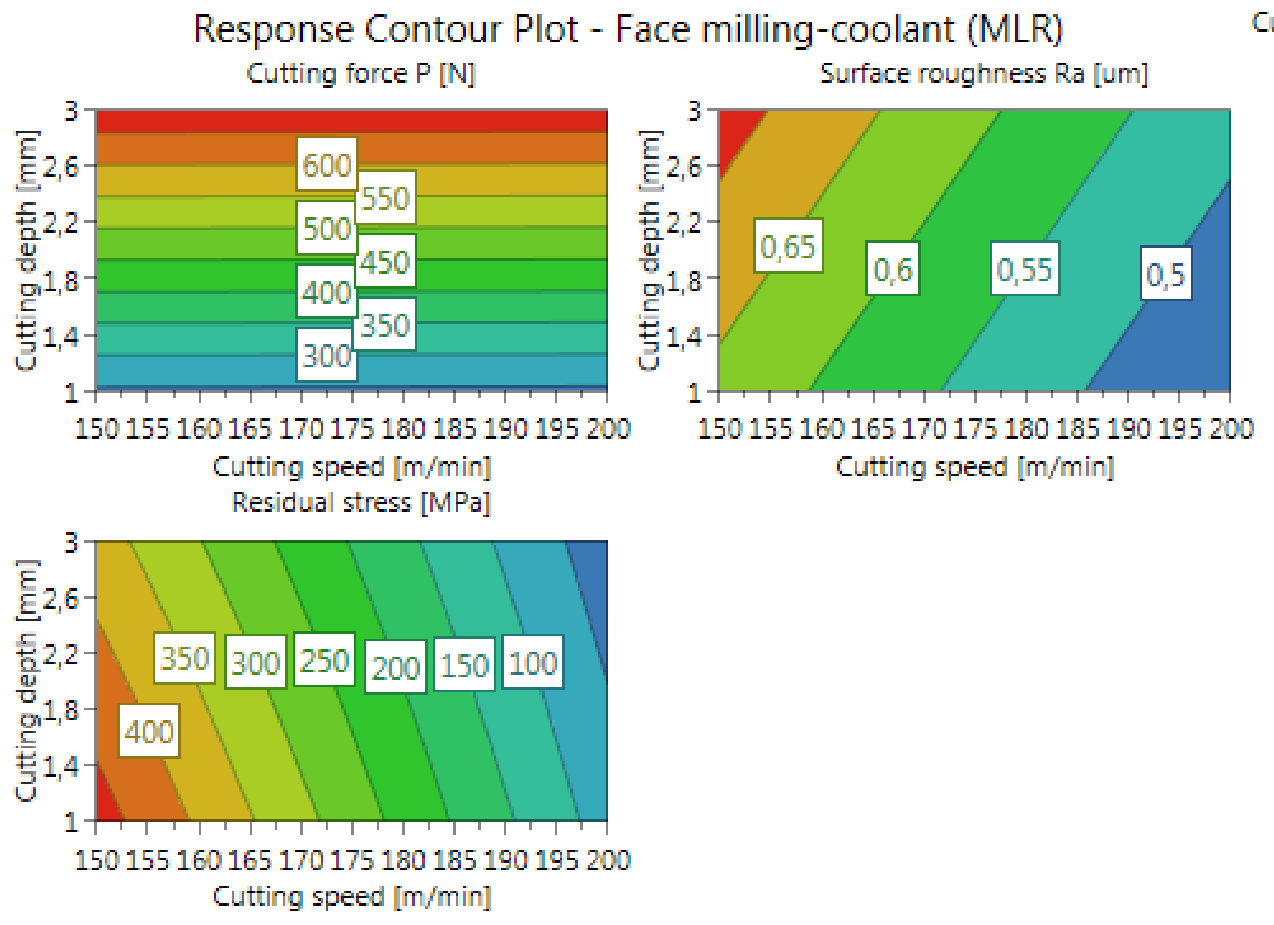

Cutting feed $=0,15$

Fig. 3. Predicted values of residual stress, surface roughness and cutting force, when cutting parameters depth and speed are variables and cutting feed constant $f_{z}=0.15 \mathrm{~mm} \cdot \mathrm{th}^{-1}$

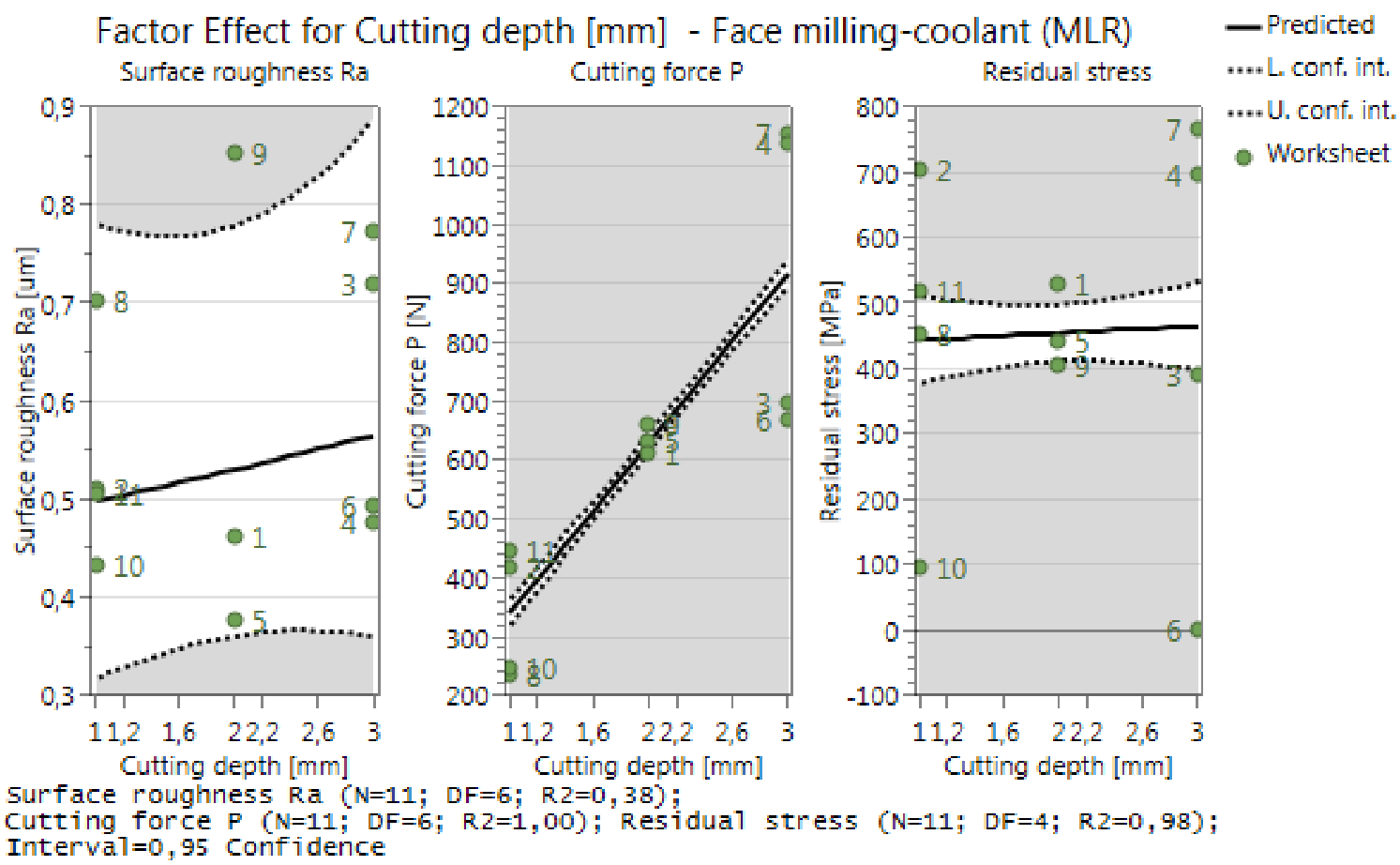

Fig. 4. Accuracy of predicted effect on value of surface roughness, cutting force and residual stress, when changing value of cutting depth $a_{p}(\mathrm{~mm})$ 


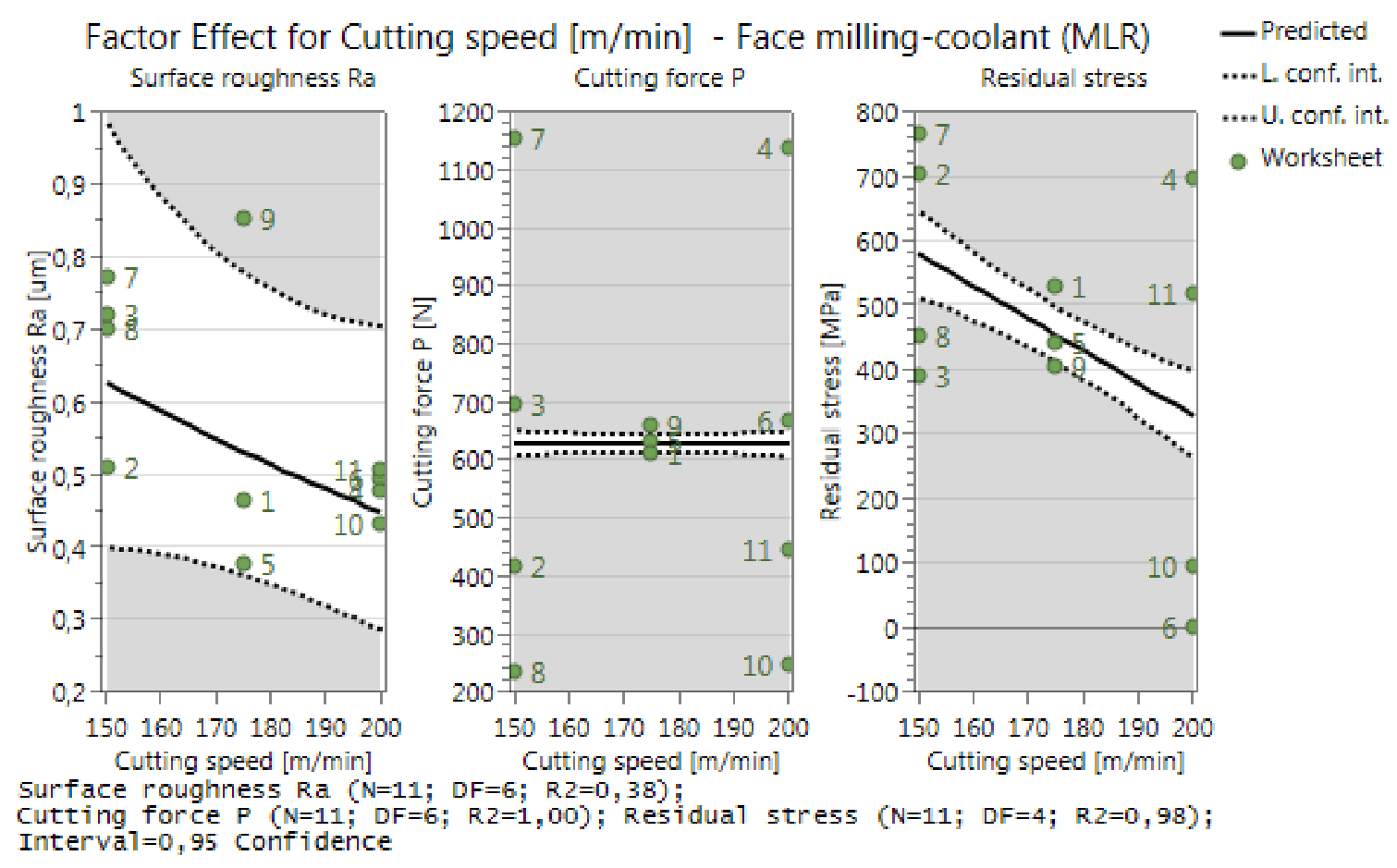

Fig. 5.Accuracy of predicted effect on value of surface roughness, cutting force and residual stress, when changing value of cutting speed $v_{c}\left(\mathrm{~m} \cdot \mathrm{min}^{-1}\right)$

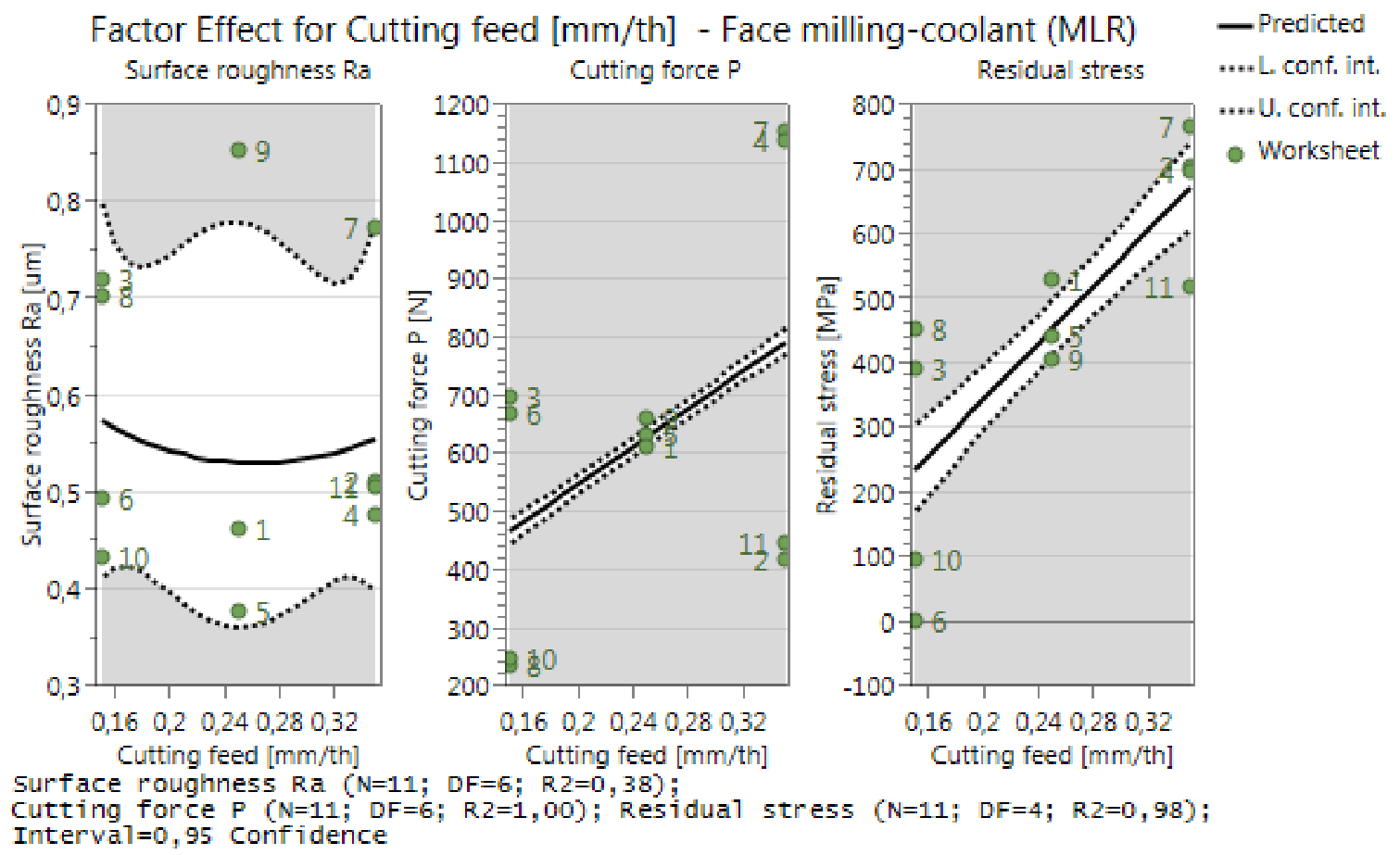

Fig. 6. Accuracy of predicted effect on value of surface roughness, cutting force and residual stress when changing value of cutting feed $f_{z}\left(\mathbf{m m} \cdot \mathbf{t h}^{-1}\right)$

\section{Residual stress}

Fig. 7a shows variations of responses for the value of residual stress. In this graph all replicates are also close together, meaning that the acquired results are sufficient to create a good model. Values of R2 and Q2 displayed in Fig. 7b are higher than 0,5. Values of model validity and reproducibility are high enough to indicate that the model fit has been achieved. The created model (Fig. 7d) suggests that 
the predicted values of residual stress grow linearly. In this case observed values confirm this prognosis. Given results in Fig. 7c show that mainly the cutting feed influences the value of residual stress. The second influencer is the cutting speed. The cutting depth alone has no significant effect on the value, but together with the cutting feed minimal reaction is observed.

To the value of the residual stress, likewise to the value of the cutting force the same parameter that makes a difference is the cutting feed. That allows predict what will the value be of the residual stress, when changing the cutting parameters depth, speed and cutting feed are constant. Prediction given in Fig. 2 suggests that the deeper and faster you cut with feed on the value $0.35 \mathrm{~mm} \cdot \mathrm{th}^{-1}$, the residual stress value decreases. In Fig. 3 the same effect has been observed with the cutting feed value being constant $0,15 \mathrm{~mm} \cdot \mathrm{th}^{-1}$. To see the accuracy of the prediction we need to look at Fig. 4-6, where R2 value of 0,98 changes liability of given prediction. However, this value is high enough, to say in $95 \%$ confidence that changing the value of the cutting feed is increasing and changing the value of the cutting speed is decreasing the value of residual stress. There is no effect, when changing only the cutting depth.

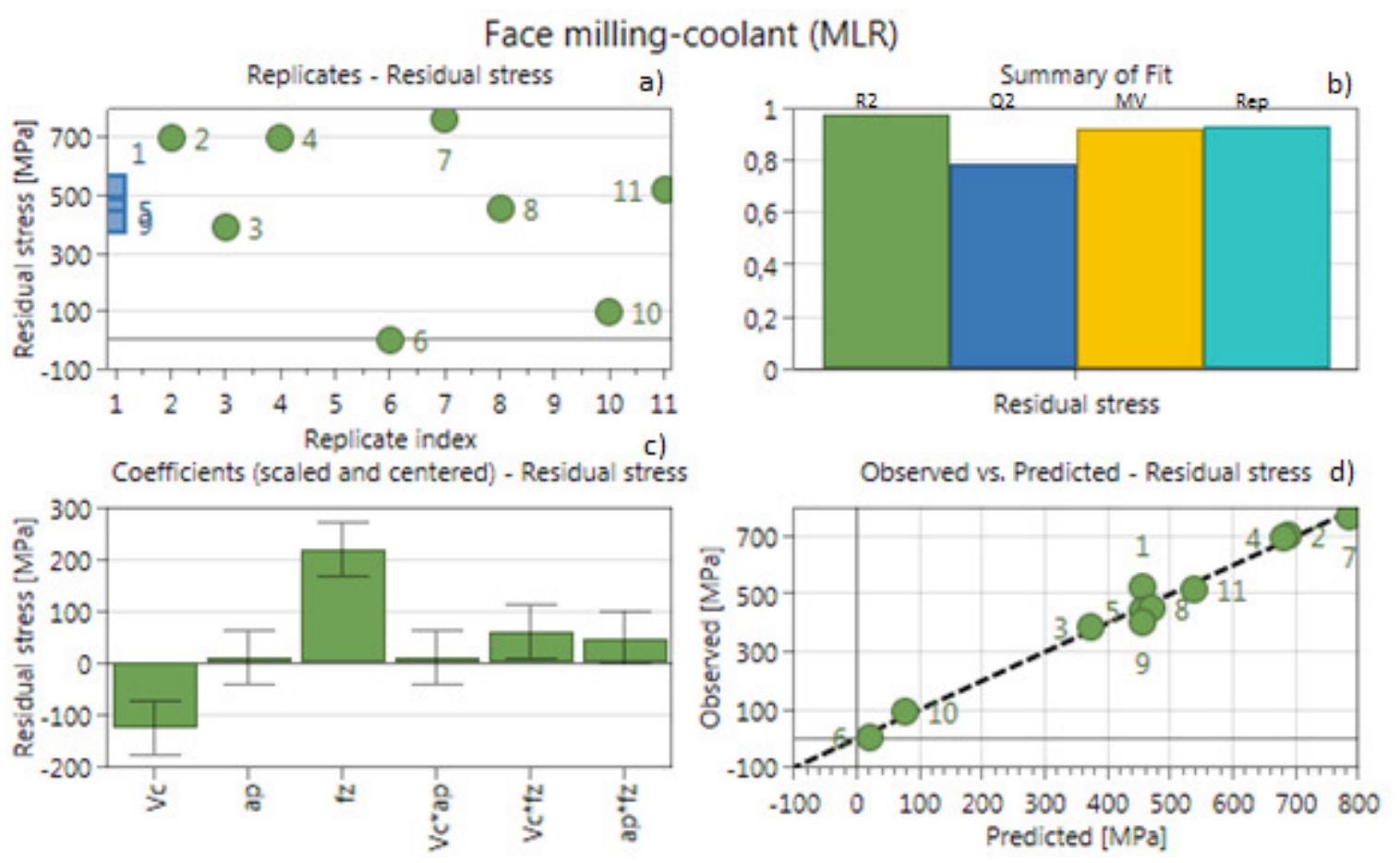

Fig. 7. Statistical comparison between predicted and collected data of residual stress:

$\mathrm{a}$ - replicate plot; $\mathrm{b}$ - model validity parameters; $\mathrm{c}$ - cutting parameter effect to value of residual stress; $\mathrm{d}$ - outcome of response versus predicted values

\section{Surface roughness}

Analysing the specimen surface roughness no definite patterns in the measured values were observed. That is shown in Fig. 8a, where it can be seen that replicates are not close together and in Fig. 8d, as the observed values are scattered. Both graphs indicate that probability to get a nonsignificant model is high. In Fig. 8b the difference between R2 and Q2 is high. To get a good model the difference should be less than 0,3 , but in this case it is 0,98 . In the same graph model the Rep value is lower than 0.5 , which is the minimum value to get a good model. Only the parameter MV has a high result, which means that the created model is correct and there are no diverse model problems. In Fig. $8 \mathrm{c}$ it can be seen that in this experiment any of the cutting parameter values had a bigger effect than others on the surface roughness value.

With this model it is not possible to predict firmly the value of surface roughness. In Fig. 4-6 there are given predicted reactions, like a bigger cutting depth raises the value of surface roughness and higher cutting speed lowers it. But all in all, the white area in these graphs indicates that these 
predictions are far from accuracy. Therefore, it is not possible to confirm that these predictions help get the surface that is needed.

Face milling-coolant (MLR)
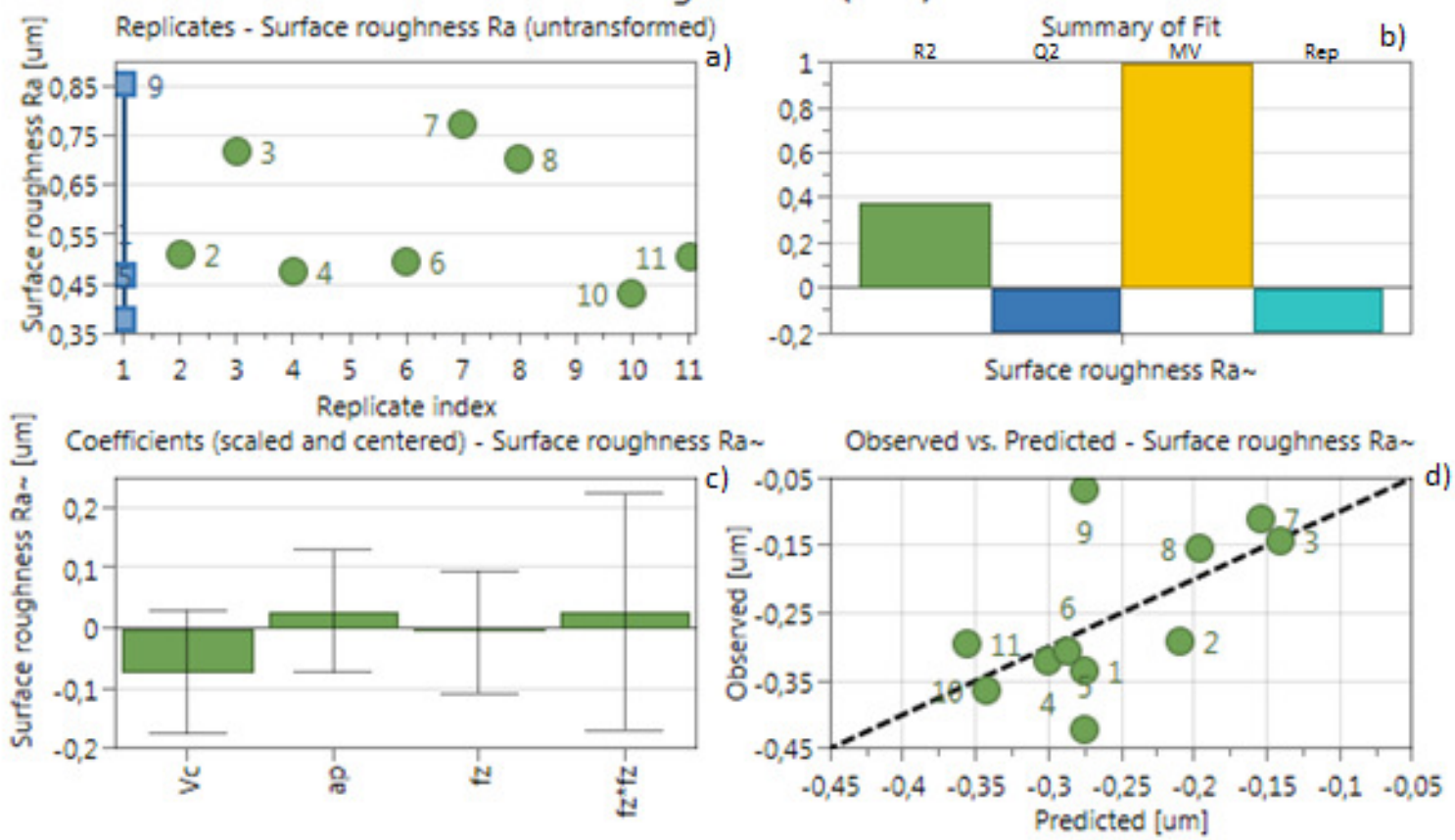

Fig. 8. Statistical comparison between predicted and collected data of surface roughness:

$\mathrm{a}$ - replicate plot; $\mathrm{b}$ - model validity parameters; $\mathrm{c}$ - cutting parameter effect to value of surface roughness; $\mathrm{d}$ - outcome of response versus predicted values

Investigating the material surface integrity, the surface roughness, cutting force and residual stresses were measured. The results were assembled and compared with statistical prediction. Model fit means that all observed values are nearly the same as predicted. In this case the statistical model created for residual stress and cutting force has a significant value, the model created to see the links between the value of surface roughness and the cutting parameters is vague. In the part where coolant was used to cool down and chip removal predicted values coincided with the observed values very well. However, in the part where compressed air was used the proportion between given results and predicted values was too big. This means that the results were scattered and no concrete relations have been found. The created statistical model was insufficient for further analysis.

With this study it can be said that the surface integrity of the material AISI 316L depends mostly on the value of the cutting feed and depth. When both cutting parameters are rather high, the probability to get bad material surface quality and internal structure is also high. Most likely it may result with fractures in the material, which will lead to the phenomenon of stress corrosion cracking in corrosive environment. To lower the possibility of material fracture it is essential to lower the impact of residual stresses.

\section{Conclusions}

For evaluating effects of the cutting parameters on material AISI 316L surface integrity statistical models were created. These models give sturdy assessment which cutting parameters are likely to decrease the quality of material after material processing.

In this study the cutting force and residual stresses were measured to assess which cutting parameter is related to stress corrosion cracking, and parameters influence to material mechanical properties. Material mechanical properties change every time when any type of material processing is conducted.The study showed that the cutting depth has the biggest effect on the value of the cutting force. Second to the cutting depth was the cutting feed. Changing the value of the cutting speed had no effect on the value of the cutting force.However, given results show growth in residual stresses, when changing the cutting feed, and fall, when changing the cutting speed. The influence of the cutting 
depth is not so clear in the given model. Based on the results obtained it is possible to infer that regards to stress corrosion cracking and changes in the material mechanical properties both are caused by changing the value of the cutting feed in material mechanical processing. In regard to the material profile, the parameter to observe was the surface roughness. Conducted model indicated that there are no concrete links between the specific cutting parameters. Therefore, it can be assumed that all cutting parameters have similar effect on the value of surface roughness or there is a need for further testing.

The models created for this study gave overall estimation which cutting parameters have greater effect on the material AISI 316L surface integrity. But to get more precise results for further investigation the conditions of the research should be changed. In this current experiment there were in total 22 specimens, of which 11 data (cut with compressed air) showed nothing precise. That means, there were too many variables that could affect the outcome.

\section{Acknowledgements}

The work was supported by the EU FP7 programme NUGENIA-PLUS (Project no. 604965) and European Regional Fund ERF, Project No. 2014-2020.4.01.16-0183, Smart Industry Centre (SmartIC).

\section{References}

[1] Allen T., Busby J., Meyer M., Petti D. Materials challenges for nuclear systems. Mater Today, vol. 13, no 12, 2010, pp. 14-23.

[2] Zinkle S. J., Was G. S. Materials challenges in nuclear energy. Acta Mater, vol. 61, no 3, 2013, pp. 735-758.

[3] M'Saoubi R., Outeiro J. C., Chandrasekaran H., Dillon Jr. O. W., Jawahir I. S. A review of surface integrity in machining and its impact on functional performance and life of machined products. International Journal of Sustainable Manufacturing, vol 1 no 1/2, 2008, pp. 203-236.

[4] Chang L., Burke M. G., Scenini F. Stress corrosion crack initiation in machined type 316L austenitic stainless steel in simulated pressurized water reactor primary water. Corrosion Science, vol. 138, no September 2017, 2018, pp. 54-65.

[5] Zhang W., Fang K., Hu Y., Wang S., Wang X. Effect of machining-induced surface residual stress on initiation of stress corrosion cracking in 316 austenitic stainless steel. Evaluation and Program Planning, vol. 108, 2016, pp. 173-184.

[6] Liu M., Takagi J., Tsukuda A. Effect of tool nose radius and tool wear on residual stress distribution in hard turning of bearing steel. Journal of Materials Processing Technology, vol. 150, 2004, pp. 234-241. 